\title{
Update on tolterodine extended-release for treatment of overactive bladder
}

This article was published in the following Dove Press journal:

Open Access Journal of Urology

22 November 2010

Number of times this article has been viewed

\section{Tola Omotosho Chi Chiung Grace Chen}

Women's Center for Pelvic Health, Department of Gynecology and Obstetrics, Johns Hopkins School of Medicine, Baltimore, MD, USA
Correspondence: Tola Omotosho Women's Center for Pelvic Health, Department of Gynecology and Obstetrics, Johns Hopkins University School of Medicine, 4940 Eastern Avenue, Room I2I, Baltimore, MD 2I 224-2780, USA

$\mathrm{Tel}+\mathrm{I} 4105500336$

Fax +I 4I0 5500245

Email tomotosI@jhmi.edu
Abstract: Overactive bladder is a prevalent condition which negatively impacts quality of life and puts a significant economical burden on society. First-line therapy often includes pharmacotherapy with antimuscarinic medications, and numerous research studies have demonstrated that tolterodine extended-release (ER) is an efficacious and tolerable formulation of this class of medication. This review provides an update on the clinical use of tolterodine ER, detailing the current literature on its efficacy, tolerability, adverse effects, and comparability with other commonly prescribed medications for the treatment of overactive bladder.

Keywords: antimuscarinics, efficacy, quality of life, overactive bladder, tolterodine, urgency, urge urinary incontinence

\section{Background}

Overactive bladder $(\mathrm{OAB})$ is a symptom syndrome defined by the International Continence Society as urgency with or without urge incontinence, usually with increased frequency and nocturia. ${ }^{1}$ This chronic prevalent condition affects both men and women, with slightly more prevalence in women $(12.8 \%$ versus $10.8 \%$, respectively, based in a population-based survey of patients in five countries). ${ }^{2}$ This condition has been shown to have a great economic impact on society as a whole, in addition to having a profound negative impact on health-related quality of life (HRQoL) of affected individuals. ${ }^{3,4}$ Treatment options for OAB include behavioral and lifestyle interventions and pharmacotherapy, with antimuscarinic medications often being first-line treatment. ${ }^{5}$ Tolterodine was one of the first in this class of medications designed specifically for the treatment of $\mathrm{OAB}$, and in 2001 once-daily tolterodine extended-release (ER) became available as an efficacious and more tolerable formulation compared with the twice-daily immediate-release (IR) form of the medication. ${ }^{6,7}$ This article provides an update on the clinical use of tolterodine ER for the treatment of OAB.

\section{Pharmacology}

Tolterodine ER is a nonselective competitive muscarinic receptor antagonist. After oral administration, tolterodine is metabolized in the liver, resulting in the formation of the 5-hydroxymethyl derivative, a pharmacologically active metabolite. The 5-hydroxymethyl metabolite, which exhibits an antimuscarinic activity similar to that of tolterodine, contributes significantly to the therapeutic effect. Compared with the IR formulation, once-daily tolterodine ER releases the drug in a steady but constant manner, lowering peak and trough drug levels. 


\section{Clinical efficacy}

\section{Tolterodine extended-release versus immediate-release}

Tolterodine ER became available in 2001 as a once-daily formulation to improve the tolerability and compliance of patients with OAB using the tolterodine IR twice-daily regimen. Theoretically, once-daily medication regimens are more convenient for patients, and a meta-analysis of 50 randomized, controlled clinical trials of antimuscarinic medications for the treatment of OAB demonstrated that the ER formulations of this class of medications were more tolerable and effective than the IR formulations. The authors of this metaanalysis concluded that the ER formulations are preferable to the IR forms of this medication. ${ }^{8}$ One large multicenter, double-blind, placebo-controlled trial conducted in 2001 by van Kerrekbroeck et al (Table 1) looked specifically at the efficacy and safety of tolterodine ER compared with the IR formulation of tolterodine and found similar results. ${ }^{7}$ A total of 1529 patients (both men and women) with OAB and urinary urge incontinence symptoms were randomized to either $4 \mathrm{mg}$ once-daily dosing of tolterodine ER, $2 \mathrm{mg}$ twice-daily dosing of tolterodine IR, or placebo for 12 weeks. Both tolterodine ER and IR were significantly more effective in the reduction of incontinence episodes $(P=0.0001$ and $P=0.005$, respectively) when compared with placebo. Furthermore, when tolterodine ER was compared with tolterodine IR, the ER formulation was $18 \%$ more effective in reducing incontinence episodes $(P<0.05)$, with less occurrence of the dry mouth side effect ( $23 \%$ versus $30 \%$ in the IR group, $P<0.02$ ). ${ }^{7}$

\section{Urinary urgency and urinary urge incontinence}

Urinary urgency is one of the hallmark symptoms of OAB, and several pivotal studies have shown improvement in urgency in patients treated with tolterodine ER; in one such study when compared with placebo, $44 \%$ of patients treated with tolterodine ER had significant improvement in urgency symptoms $(P<0.001)$. In addition, the percentage of patients unable to hold their urine in response to urgency was significantly reduced by $58 \%$ in the patients treated with tolterodine ER versus only $32 \%$ in the placebo group $(P<0.001) .{ }^{9}$ In another randomized, double-blind, placebo-controlled trial, the efficacy of tolterodine ER in 854 patients with mixed incontinence and predominant urge incontinence was compared with placebo after eight weeks of treatment, ${ }^{10}$ and $4 \mathrm{mg}$ once-daily dosing of tolterodine ER was found to be successful in reducing urinary urge incontinence episodes $(P<0.0001)$, urge episodes, and urinary frequency (both $P<0.0001$ ). In addition, the median voided volume increased significantly when compared with placebo $(P<0.0001){ }^{10}$

\section{Night-time voiding symptoms}

Night-time dosing of tolterodine ER has been shown to decrease nocturnal OAB micturitions significantly and still maintain clinical efficacy throughout the day. In a study of 850 patients randomized to 12 weeks of treatment with either placebo or $4 \mathrm{mg}$ tolterodine ER administered four hours or sooner before bedtime, there were significant reductions in $\mathrm{OAB}$ nocturnal micturitions in the tolterodine ER group $(P=0.0086)$. Tolterodine ER also significantly reduced both 24 hours and daytime intervals. Serious side effects were reported in $1.2 \%$ of patients in this study, and all of these effects were considered to be unrelated to treatment. ${ }^{11}$ Another study also determined that tolterodine ER maintained clinical efficacy over 24 hours and should be effective for OAB symptoms, without regard to whether symptoms occur during the day or at night. ${ }^{12}$

Table I Summary of tolterodine extended-release efficacy studies

\begin{tabular}{|c|c|c|c|}
\hline Authors & Study population & Study design & Efficacy \\
\hline van Kerrekbroek et $\mathrm{al}^{7}$ & $\begin{array}{l}\text { A total of } 1529 \text { men } \\
\text { and women with urinary } \\
\text { frequency and urge incontinence }\end{array}$ & $\begin{array}{l}\text { Randomized, double-blind } \\
\text { placebo-controlled trial } \\
\text { comparing tolterodine } \\
\text { ER with IR and placebo }\end{array}$ & $\begin{array}{l}\text { Tolterodine ER and IR formulations significantly } \\
\text { reduced incontinence episodes compared with } \\
\text { placebo. Tolterodine ER was more effective } \\
\text { at reducing incontinence episodes than IR }\end{array}$ \\
\hline Rackley et al'" & $\begin{array}{l}850 \text { patients with } \mathrm{OAB} \\
\text { and nocturia }\end{array}$ & $\begin{array}{l}\text { Randomized, placebo-controlled } \\
\text { trial, double-blind study of } 4 \mathrm{mg} \\
\text { tolterodine ER and placebo }\end{array}$ & $\begin{array}{l}\text { Significantly reduced OAB-related and severe } \\
\text { OAB nocturnal micturitions compared with } \\
\text { placebo. Total number of nocturnal } \\
\text { micturitions was reduced compared with } \\
\text { placebo but this was not statistically significant }\end{array}$ \\
\hline Dmochowski et al ${ }^{12}$ & Patients with $\mathrm{OAB}$ and UUI & $\begin{array}{l}\text { Post hoc analysis of a I } 2 \text {-week, } \\
\text { placebo-controlled trial of } \\
\text { tolterodine ER } 4 \mathrm{mg} \text { and placebo } \\
\text { effect on specific day-time and } \\
\text { night-time intervals over } 24 \text { hours }\end{array}$ & $\begin{array}{l}\text { Tolterodine ER maintained clinical efficacy } \\
\text { over a 24-hour period, and significantly and } \\
\text { consistently increased voided volume and } \\
\text { reduced UUl episodes and voiding frequency }\end{array}$ \\
\hline
\end{tabular}

Abbreviations: $O A B$, overactive bladder; UUI, urinary urge incontinence; ER, extended-release; IR, immediate release. 


\section{Urodynamic parameters}

A total of 111 women with a urodynamic diagnosis of detrusor overactivity were prospectively divided into two groups, one with involuntary detrusor contractions during the cystometric filling phase (Group 1) and the other after provocative maneuvers (Group 2). Both groups were prescribed $4 \mathrm{mg}$ once-daily tolterodine ER. After 12 weeks, there was a significant difference $(P=0.0008)$ between the groups in terms of the efficacy of tolterodine ER, with a better response rate in Group 1. The authors concluded that the efficacy of tolterodine ER may be related to the different urodynamic findings for detrusor overactivity. ${ }^{13}$

\section{HRQoL parameters}

The long-term effects of tolterodine ER on HRQoL in patients diagnosed with $\mathrm{OAB}$ and incontinence were assessed in a randomized, double-blind, safety and efficacy trial comparing tolterodine ER with placebo in a 12-month openlabel continuation trial. HRQoL information was obtained from the King's Health Questionnaire (KHQ) and the Short Form-36 that were administered at baseline, at the end of the 12-week trial, and three and 12 months following open-label treatment with tolterodine ER. One thousand and seventyseven patients were included in the intent-to-treat (ITT) population. KHQ translations were available for 838 patients (mean age 61.1 years, $80.9 \%$ women) in the ITT population. HRQoL, as measured by the KHQ, significantly improved from baseline to months 3 and 12 for impact on incontinence, role limitations, physical limitations, social limitations, personal relationships, emotions, sleep and energy, severity (coping) measures, and symptom severity. ${ }^{14}$ Other studies have evaluated the effect of $4 \mathrm{mg}$ tolterodine $\mathrm{ER}$ on $\mathrm{OAB}$ symptoms and sexual and emotional health in women. In an early study, 413 sexually active women were randomized to placebo or tolterodine ER, and at 12 weeks, the tolterodine ER group had a significant reduction in urinary urge incontinence episodes and total urinary incontinence episodes ( $P=0.0029$ and $P=0.0006$, respectively). ${ }^{15}$ This group also had significant improvement in sexual health measures. ${ }^{15}$ A secondary analysis of this study was performed in 161 patients who continued tolterodine ER for 24 weeks, and improvements in $\mathrm{OAB}$ symptoms and HRQoL parameters were maintained. ${ }^{16}$

\section{Comparison with other antimuscarinics}

In a Cochrane systematic review of 61 placebo-controlled trials of various anticholinergic medications, the reviewers found significant improvement in symptoms in people taking anticholinergics, including a decrease in leakage episodes during 24 hours ( -0.54 weighted mean difference [WMD]; $95 \%$ confidence interval $[\mathrm{CI}]:-0.67$ to -0.41$)$ and a decrease in number of voids in 24 hours $(-0.69 \mathrm{WMD} ; 95 \% \mathrm{CI}:-0.84$ to -0.54 ), as well as improved HRQoL scores. ${ }^{17}$ The active medication groups experienced more dry mouth (relative risk [RR] 3.0; 95\% CI: 2.70-3.34) but treatment withdrawal rates were similar between the active medication and placebo groups (RR 1.11; 95\% CI: 0.91-1.36). Sensitivity analysis demonstrated a low likelihood that the findings were affected by type of medication, age or gender of participants, or their diagnosis. ${ }^{17}$ In a previous Cochrane systematic review of 49 trials including 11,332 patients published in 2005 comparing different anticholinergic medications, the authors found that oxybutynin and tolterodine were similarly efficacious, but there were insufficient data to draw any conclusions regarding the other anticholinergic medications. The ER formulations of both oxybutynin and tolterodine were favored over the IR agents, due to a decrease in side effects, including dry mouth. ${ }^{18}$ Another systematic review which included 56 randomized, controlled trials and 17,692 patients concluded that most anticholinergic medications, including IR and ER tolterodine, were well tolerated compared with placebo, and with the exception of IR oxybutynin. ${ }^{19}$ A summary of both tolterodine formulations (IR and ER) with specific comparison against commonly prescribed anticholinergic medications is provided here.

\section{Oxybutynin}

There are two randomized, actively controlled trials comparing ER tolterodine and ER oxybutynin. ACET (Antimuscarinic Clinical Effectiveness Trial) involved two parallel studies with identical protocols that compared two doses of ER tolterodine ( $2 \mathrm{mg}$ and $4 \mathrm{mg}$ ) in 669 subjects, and two doses of ER oxybutynin ( $5 \mathrm{mg}$ and $10 \mathrm{mg}$ ) in 620 subjects. $^{20}$ After eight weeks, subjects in the $4 \mathrm{mg}$ tolterodine group experienced greater improvement in bladder symptoms than subjects in the $2 \mathrm{mg}$ tolterodine group or the oxybutynin groups. Although participants in both groups experienced some dose-dependent increases in side effects, fewer participants withdrew from the $4 \mathrm{mg}$ tolterodine group compared with both oxybutynin groups (12\% versus $19 \%$ and $21 \%$, $P=0.01$ and $P=0.002) .{ }^{20}$

The OPERA (Overactive Bladder Performance of Extended Release Agents) trial involved 790 women with $\mathrm{OAB}$ from 71 centers who were randomized to either $4 \mathrm{mg}$ of ER tolterodine or $10 \mathrm{mg}$ of ER oxybutynin for 12 weeks. ${ }^{21}$ Although more women in the oxybutynin group experienced episodes of no incontinence ( $23 \%$ versus $17 \%, P=0.03$ ) and 
decreased micturition frequency, there were no differences in the average weekly urge incontinence episodes. The differences in efficacy between oxybutynin and tolterodine were seen more often in women who had previously taken anticholinergic medications than in anticholinergic-naïve women. ${ }^{22}$ More women who took oxybutynin experienced dry mouth ( $30 \%$ versus $22 \%, P=0.02)$, but the discontinuation rates were similar between the groups. Despite the higher lipid solubility of tolterodine, rates of adverse central nervous system events were also low and similar between the groups ( $8 \%$ for tolterodine and $9 \%$ for oxybutynin). ${ }^{23}$ ER tolterodine has also been compared with transdermal oxybutynin, with comparable efficacy results. ${ }^{24}$ More patients experienced local skin irritation in the transdermal oxybutynin group.

\section{Solifenacin}

In STAR (solifenacin versus tolterodine randomized trial), $5 \mathrm{mg}$ or $10 \mathrm{mg}$ of solifenacin was compared with $4 \mathrm{mg}$ of ER tolterodine in 1177 men and women. ${ }^{25}$ In this trial, the participants could choose to increase the dose of solifenacin up to $10 \mathrm{mg}$ after four weeks of usage. After 12 weeks, solifenacin was found to be similar to tolterodine in terms of decreasing the frequency of daily voids. Participants in the solifenacin group had significantly greater improvements in episodes of urgency, urge incontinence, and overall incontinence compared with baseline than subjects in the tolterodine group. More subjects in the solifenacin group experienced at least a $50 \%$ reduction in incontinence episodes or experienced total continence with decreased incontinence pad usage than subjects in the tolterodine group. Although more patients experienced side effects in the solifenacin group, these differences were not statistically significant, and the overall discontinuation rates in both groups were low (3.5\% in the solifenacin group and 3\% in the tolterodine group).

\section{Propiverine}

Tolterodine $2 \mathrm{mg}$ twice daily was compared with propiverine $15 \mathrm{mg}$ twice daily in a randomized, multicenter study in patients with detrusor overactivity over the course of 28 days. ${ }^{26}$ Both agents were comparable in terms of patient improvement in HRQoL, efficacy, and tolerability.

\section{Fesoterodine}

In randomized, placebo- and active-controlled study designed to address the efficacy, tolerability, and safety of fesoterodine, a prodrug which is metabolized to the same active metabolite as tolterodine (5-hydroxymethyl tolterodine), participants taking $4 \mathrm{mg}$ or $8 \mathrm{mg}$ fesoterodine or $4 \mathrm{mg}$ tolterodine experienced a decrease in micturition episodes, urgency episodes, and urge incontinence episodes, and improve HRQoL compared with the placebo group. ${ }^{27}$ Although this study was not designed to compare fesoterodine with tolterodine, the authors published a post hoc analysis reporting that subjects in the $8 \mathrm{mg}$ fesoterodine group had significantly greater improvement in urge incontinence episodes, mean voided volume, and number of continent days per week than subjects in the tolterodine group. ${ }^{28}$ The rates of medication discontinuation was similar between the groups $(2 \%$ placebo, $3 \%$ tolterodine, $5 \%$ fesoterodine). However, more subjects in the $8 \mathrm{mg}$ fesoterodine group experienced side effects, including dry mouth (34\% fesoterodine, 17\% tolterodine, $7 \%$ placebo). In another randomized, placebo-controlled trial designed to compare the efficacy and tolerability of $8 \mathrm{mg}$ fesoterodine with that of $4 \mathrm{mg}$ ER tolterodine, more patients taking fesoterodine reported no episodes of urge incontinence than subjects taking tolterodine (64\% versus 57\%; $P=0.015) .{ }^{29}$ Participants taking fesoterodine also reported greater improvements in urge incontinence, mean voided volume, and decreased micturition episodes, along with greater improvements in most HRQoL assessments. Discontinuation rates were similar between groups.

\section{Trospium chloride}

Although the efficacy of tolterodine has not been compared with trospium chloride, there was a study that addressed electroencephalographic (EEG) changes in patients after taking ER tolterodine compared with trospium chloride and oxybutynin..$^{30}$ Despite being a tertiary amine and being able to cross the blood-brain barrier, tolterodine was found to cause minimal EEG changes and was comparable with trospium, which is a quaternary amine that does not enter the central nervous system to a significant extent. Oxybutynin, also a tertiary amine, caused more EEG changes than tolterodine and trospium.

\section{Adverse effects}

Both IR and ER tolterodine have been extensively studied and found to be tolerable, having similar side effect profiles, with the IR formulation resulting in more adverse events. In a randomized, placebo-controlled trial comparing the efficacy and tolerability of ER tolterodine and IR tolterodine, the ER agent was more effective at reducing incontinence episodes than IR tolterodine, with decreased reporting of dry mouth 
( $23 \%$ versus $30 \%)$ and similar rates of withdrawal, even when compared with placebo. ${ }^{7}$

In another study addressing adherence and switch rates for the IR and ER formulations of tolterodine and oxybutynin, the authors found that the ER formulations resulted in higher adherence rates compared with the IR formulation (35\% for ER tolterodine, 24\% for IR tolterodine, 36\% for ER oxybutynin, $15 \%$ for IR oxybutynin; $P<0.001) .{ }^{31}$ The overall switch rate was $13 \%$, with fewer patients switching from ER tolterodine than from the other agents $(10 \%$ for ER tolterodine, 14\% for IR tolterodine, $17 \%$ for ER oxybutynin, $19 \%$ for IR oxybutynin; $P=0.020$ ), with an overall median time to discontinuation of 31 days.

Discontinuation rates for all antimuscarinic medications used in the treatment of OAB are high. Specifically, a large database review of 29,369 women with 49,419 episodes of anticholinergic medication therapy found the adjusted cumulative incidence of medication discontinuation for IR tolterodine was 61\% (95\% CI: 59.4-64.3) and for ER tolterodine was $54 \%$ (95\% CI: 52.3-57.7) at six months. ${ }^{32}$ The median time to discontinuation of any medication was 4.8 months. In a study addressing medication adherence in the US Military Health System National Capital Region, in which patients do not pay for medication, the most commonly dispensed anticholinergic was ER tolterodine (60\%), followed by IR oxybutynin $(26 \%) .{ }^{33}$ Patients taking ER tolterodine were found to have a higher rate of not refilling the prescription than subjects taking IR oxybutynin $(89 \%$ versus $68 \% ; P<0.01)$.

\section{Xerostomia}

Xerostomia, or dry mouth, is the most commonly reported side effect in patients taking anticholinergic medications. In the original placebo-controlled study addressing the efficacy and safety of tolterodine, the incidences of dry mouth were $30 \%$ for the IR agent, $23 \%$ for the ER formulation, and $8 \%$ for placebo. ${ }^{7}$ Although tolterodine does not selectively bind muscarinic receptor subtypes found in the urinary tract, it has been shown to have functional selectivity for these receptor subtypes over receptors in the salivary gland. ${ }^{34,35}$ In a clinical study comparing ER tolterodine with oxybutynin, fewer subjects taking tolterodine had dry mouth $(22 \%$ versus $30 \% ; P=0.02) .{ }^{20}$

\section{Blurry vision and xerophthalmia}

Tolterodine can affect smooth muscle in the iris, and has been found to cause blurry vision in $1 \%$ of subjects. ${ }^{7}$ It can also inhibit lacrimation, and was found to result in xerophthalmia in $2 \%-3 \%$ of cases.

\section{Gastrointestinal effects}

Like other anticholinergic agents, tolterodine does decrease gastrointestinal motility. However, it has not been consistently found to result in significant gastrointestinal side effects. In the original efficacy and safety study, subjects taking tolterodine had similar constipation rates when compared with participants taking placebo. ${ }^{7}$ However, in a randomized, placebo-controlled trial specifically addressing the gastrointestinal effects of ER tolterodine $4 \mathrm{mg}$, tolterodine was not found to cause significant changes in gastrointestinal transit time, but patients taking the medication did have fewer bowel movements $(1.0 \pm 0.1$ versus $1.34 \pm 0.1 ; P=0.02)$, without any changes in ease of defecation or stool consistency. ${ }^{36}$

\section{Central nervous system effects}

Although tolterodine does cross the blood-brain barrier, it has not been found to cause significant EEG changes. ${ }^{30}$ However, there have been reports in the literature of impaired cognitive function in the elderly and in patients with Alzheimer's disease taking this medication. ${ }^{37,38}$

\section{Cardiac effects}

In one study, patients taking ER tolterodine were found to have increased heart rates compared with subjects taking darifenacin or placebo, with more patients experiencing increased heart rates. ${ }^{39} \mathrm{In}$ another trial, IR tolterodine $2 \mathrm{mg}$ or $4 \mathrm{mg}$ twice daily was not found to have a significant effect on QT interval. ${ }^{40}$ In healthy female volunteers, high doses of ER tolterodine at $8 \mathrm{mg}$, but not at $4 \mathrm{mg}$, have also been found to reduce resting heart rate variability, which is an important predictor for cardiac mortality. ${ }^{41}$

\section{Cost-effectiveness}

A cost-utility analysis was performed as part of a systematic review and meta-analysis of the efficacy and safety of antimuscarinics, consisting of solifenacin, tolterodine IR and ER formulations, darifenacin, fesoterodine, and oxybutynin. The analysis included costs directly associated with treatment for $\mathrm{OAB}$, ie, antimuscarinic therapy, consultations with general practitioners, and outpatient contacts. The study was conducted in the UK and costs were reported at 2007 and 2008 prices. Tolterodine ER was determined to be less cost-effective when compared with solifenacin for the treatment of OAB. ${ }^{42}$

\section{Conclusion}

$\mathrm{OAB}$ is a prevalent and often life-altering condition. The purpose of any form of treatment is to reduce symptoms of urinary urgency and frequency and urge incontinence 
episodes, and to improve the overall HRQoL effectively in patients with this symptom syndrome. Antimuscarinic pharmacotherapy, such as tolterodine ER, is often used as first-line treatment. Several research studies have demonstrated tolterodine ER to be an effective, tolerable, and safe therapeutic option for patients with $\mathrm{OAB}$.

\section{Disclosure}

TBO has previously received research funding from Pfizer for an investigator-initiated research study

\section{References}

1. Abrams P, Cardozo L, Fall M. The standardisation of terminology in lower urinary tract function: Report from the standardisation sub-committee of the International Continence Society. Urology. 2003;61(1):37-49.

2. Irwin DE, Milsom I, Hunskaar S, et al. Population-based survey of urinary incontinence, overactive bladder, and other lower urinary tract symptoms in five countries: Results of the EPIC study. Eur Urol. 2006; 50(6):1306-1314.

3. Irwin DE, Mungapen L, Milsom I, Kopp Z, Reeves P, Kelleher C. The economic impact of overactive bladder syndrome in six Western countries. BJU Int. 2009;103(2):202-209.

4. Coyne KS, Sexton CC, Irwin DE, Kopp ZS, Kelleher CJ, Milsom I. The impact of overactive bladder, incontinence and other lower urinary tract symptoms on quality of life, work productivity, sexuality and emotional well-being in men and women: Results from the EPIC study. BJU Int. 2008;101(11):1388-1395.

5. Andersson KE. Antimuscarinics for the treatment of overactive bladder. Lancet Neurol. 2004;3:46-53.

6. Abrams P, Freeman R, Anderström C, Mattiasson A. Tolterodine, a new antimuscarinic agent: As effective but better tolerated than oxybutynin in patients with an overactive bladder. Br J Urol. 1998;81(6):801-810.

7. van Kerrebroeck P, Kreder K, Jonas U, Zinner N, Wein A; Tolterodine Study Group. Tolterodine once-daily: Superior efficacy and tolerability in the treatment of the overactive bladder. Urology. 2001;57(3): 414-421.

8. Novara G, Galfano A, Secco S, et al. A systematic review and metaanalysis of randomized controlled trials with antimuscarinic drugs for overactive bladder. Eur Urol. 2008;54(4):740-763.

9. Freeman R, Hill S, Millard R, Slack M, Sutherst J. Reduced perception of urgency in treatment of overactive bladder with extended release tolterodine. Obstet Gynecol. 2003;102(3):605-611.

10. Khullar V, Hill S, Laval KU, Schiøtz HA, Jonas U, Versi E. Treatment of urge-predominant mixed urinary incontinence with tolterodine extended release: A randomized, placebo-controlled trial. Urology. 2004;64(2):269-274.

11. Rackley R, Weiss JP, Rovner ES, Wang JT, Guan Z. Nighttime dosing with tolterodine reduces overactive bladder-related nocturnal micturitions in patients with overactive bladder and nocturia. Urology. 2006;67(4):731-736.

12. Dmochowski R, Kreder K, MacDiarmid S, Carlsson M, Guan Z. The clinical efficacy of tolterodine extended-release is maintained for $24 \mathrm{~h}$ in patients with overactive bladder. BJU Int. 2007;100(1): 107-110.

13. Salvatore S, Serati M, Digesu GA, et al. Efficacy of tolterodine in relation to different urodynamic findings of detrusor overactivity. Int Urogynecol J Pelvic Floor Dysfunct. 2008;19(5):701-704.

14. Kelleher CJ, Kreder KJ, Pleil AM, Burgess SM, Reese PR. Long-term health-related quality of life of patients receiving extended-release tolterodine for overactive bladder. Am J Manag Care. 2002; 8 Suppl 19:S616-S630.
15. Rogers R, Bachmann G, Jumadilova Z, et al. Efficacy of tolterodine on overactive bladder symptoms and sexual and emotional quality of life in sexually active women. Int Urogynecol J Pelvic Floor Dysfunct. 2008;19(11):1551-1557.

16. Rogers RG, Omotosho T, Bachmann G, Sun F, Morrow JD. Continued symptom improvement in sexually active women with overactive bladder and urgency urinary incontinence treated with tolterodine ER for 6 months. Int Urogynecol J Pelvic Floor Dysfunct. 2009;20(4): 381-385.

17. Nabi G, Cody JD, Ellis G, Herbison P, Hay-Smith J. Anticholinergic drugs versus placebo for overactive bladder syndrome in adults. Cochrane Database Syst Rev. 2006;18(4):CD003781.

18. Hay-Smith J, Herbison P, Ellis G, Morris A. Which anticholinergic drug for overactive bladder symptoms in adults. Cochrane Database Syst Rev. 2005;20(3):CD005429.

19. Urinary Incontinence. The management of urinary incontinence in women. National Institute for Health and Clinical Excellence, Oct 2006. Available at: http://www.nice.org.uk/nicemedia/ live/10996/30281/30281.pdf. Accessed 2010 Sep 29.

20. Sussman D, Garely A. Treatment of overactive bladder with oncedaily extended-release tolterodine or oxybutynin: The antimuscarinic clinical effectiveness trial (ACET). Curr Med Res Opin. 2002;18(4): 177-184.

21. Diokno AC, Appell RA, Sand PK, et al. Prospective, randomized, double-blind study of the efficacy and tolerability of the extendedrelease formulations of oxybutynin and tolterodine for overactive bladder: Results of the OPERA trial. Mayo Clin Proc. 2003;78(6): 687-695.

22. Anderson RU, MacDiarmid S, Kell S, Barada JH, Serels S, Goldberg RP. Effectiveness and tolerability of extended-release oxybutynin vs extended-release tolterodine in women with or without prior anticholinergic treatment for overactive bladder. Int Urogynecol J Pelvic Floor Dysfunct. 2006;17(5):502-511.

23. Chu FM, Dmochowski RR, Lama DJ, Anderson RU, Sand PK. Extended-release formulations of oxybutynin and tolterodine exhibit similar central nervous system tolerability profiles: A subanalysis of data from the OPERA trial. Am J Obstet Gynecol. 2005;192(6): 1849-1854.

24. Dmochowski RR, Sand PK, Zinner NR, et al. Comparative efficacy and safety of transdermal oxybutynin and oral tolterodine versus placebo in previously treated patients with urge and mixed urinary incontinence. Urology. 2003;62(2):237-242.

25. Chapple CR, Martinez-Garcia R, Selvaggi L, et al. A comparison of the efficacy and tolerability of solifenacin succinate and extended release tolterodine at treating overactive bladder syndrome: Results of the STAR trial. Eur Urol. 2005;48(3):464-470.

26. Junemann KP, Halaska M, Rittstein T, et al. Propiverine versus tolterodine: Efficacy and tolerability in patients with overactive bladder. Eur Urol. 2005;48(3):478-482.

27. Chapple C, van Kerrebroeck P, Tubaro A, et al. Clinical efficacy, safety, and tolerability of once-daily fesoterodine in subjects with overactive bladder. Eur Urol. 2007;52(4):1204-1212.

28. Chapple CR, van Kerrebroeck PE, Junemann KP, Wang JT, Brodsky M. Comparison of fesoterodine and tolterodine in patients with overactive bladder. BJU Int. 2008;102(9):1128-1132.

29. Herschorn S, Swift S, Guan Z, et al. Comparison of fesoterodine and tolterodine extended release for the treatment of overactive bladder: A head-to-head placebo-controlled trial. BJU Int. 2010; 105(1):58-66.

30. Todorova A, vonderheid-Guth B, Dimpfel W. Effects of tolterodine, trospium chloride, and oxybutynin on the central nervous system. JClin Pharmacol. 2001;41(6):636-644.

31. D’Souza AO, Smith MJ, Miller LA, Doyle J, Ariely R. Persistence, adherence, and switch rates among extended-release and immediaterelease overactive bladder medications in a regional managed care plan. J Manag Care Pharm. 2008;14(3):291-301. 
32. Gopal M, Haynes K, Bellamy SL, Arya LA. Discontinuation rates of anticholinergic medications used for the treatment of lower urinary tract symptoms. Obstet Gynecol. 2008;112(6):1311-1318.

33. Sears CL, Lewis C, Noel K, Albright TS, Fischer JR. Overactive bladder medication adherence when medication is free to patients. $J$ Urol. 2010;183(3):1077-1081.

34. Chapple CR, Nilvebrant L. Tolterodine: Selectivity for the urinary bladder over the eye (as measured by visual accommodation) in healthy volunteers. Drugs R D. 2002;3(2):75-81.

35. Stahl MM, Ekstrom B, Sparf B, Mattiasson A, Andersson KE. Urodynamic and other effects of tolterodine: A novel antimuscarinic drug for the treatment of detrusor overactivity. Neurourol Urodyn. 1995;14(6):647-655.

36. Bharucha AE, Seide B, Guan Z, Andrews CN, Zinsmeister AR. Effect of tolterodine on gastrointestinal transit and bowel habits in healthy subjects. Neurogastroenterol Motil. 2008;20(6):643-648.

37. Jewart RD, Green J, Lu CJ, Cellar J, Tune LE. Cognitive, behavioral, and physiological changes in Alzheimer disease patients as a function of incontinence medications. Am J Geriatr Psychiatry. 2005;13(4):324-328.
38. Salvatore S, Serati M, Cardozo L, Uccella S, Bolis P. Cognitive dysfunction with tolterodine use. Am J Obstet Gynecol. 2007;197(2):E8.

39. Olshansky B, Ebinger U, Brum J, Egermark M, Viegas A, Rekeda L. Differential pharmacological effects of antimuscarinic drugs on heart rate: A randomized, placebo-controlled, double-blind, crossover study with tolterodine and darifenacin in healthy participants $\leq 50$ years. J Cardiovasc Pharmacol Ther. 2008;13(4):241-251.

40. Malhotra BK, Glue P, Sweeney K, Anziano R, Mancuso J, Wicker P. Thorough QT study with recommended and supratherapeutic doses of tolterodine. Clin Pharmacol Ther. 2007;81(3):377-385.

41. Schiffers M, Sauermann P, Schurch B, Mehnert U. The effect of tolterodine 4 and $8 \mathrm{mg}$ on the heart rate variability in healthy subjects. World J Urol. 2010;28(5):651-656.

42. Cardozo L, Thorpe A, Warner J, Sidhu M. The cost-effectiveness of solifenacin vs fesoterodine, oxybutynin immediate-release, propiverine, tolterodine extended-release and tolterodine immediate-release in the treatment of patients with overactive bladder in the UK National Health Service. BJU Int. 2010;106(4):506-514
Open Access Journal of Urology

\section{Publish your work in this journal}

The Open Access Journal of Urology is an international, peer-reviewed, open access journal publishing original research, reports, editorials, reviews and commentaries on all aspects of adult and pediatric urology in the clinic and laboratory including the following topics: Pathology, pathophysiology of urological disease; Investigation and treatment of

\section{Dovepress}

urological disease; Pharmacology of drugs used for the treatment of urological disease. The manuscript management system is completely online and includes a very quick and fair peer-review system, which is all easy to use. Visit http://www.dovepress.com/testimonials.php to read real quotes from published authors.

Submit your manuscript here: http://www.dovepress.com/open-access-journal-of-urology-journal 